\title{
A possible association of partial lipodystrophy with anti-GBM nephritis (Goodpasture's syndrome)
}

\author{
D. R. BLAKE \\ M.B., Ch.B., M.R.C.P. \\ M. McHugh \\ M.B., Ch.B., M.R.C.P.
}

\author{
H. RASHID \\ M.B. B.S., F.C.P.S. \\ A. R. MORLEY \\ M.D., M.R.C.Path.
}

The Royal Victoria Infirmary, Newcastle upon Tyne

\begin{abstract}
Summary
Partial lipodystrophy is known to be associated with mesangiocapillary glomerulonephritis. A case is described of a possible association of partial lipodystrophy with anti-GBM nephritis (Goodpasture's syndrome).
\end{abstract}

\section{Introduction}

The association between partial lipodystrophy and renal disease was first noted by Gellis, Green and Walker (1958) and subsequently its association with mesangio-capillary glomerulonephritis was confirmed by other authors (Peters et al., 1973; Sissons et al., 1976).

The authors have been unable to find any previous report of an association between partial lipodystrophy and anti-GBM disease (Goodpasture's syndrome).

\section{Case report}

A 54-year-old female presented after a 3-week history of lethargy, recurrent haemoptysis and haematuria. On examination she was pale with marked facial lipodystrophy (Fig. 1), temperature $38^{\circ} \mathrm{C}$, pulse $110 / \mathrm{min}$, BP $160 / 80 \mathrm{mmHg}$. Apart from bilateral fine crepitations throughout both lung fields, systemic examination was negative. There has been no significant past medical history and no family history of hypertension, renal disease or lipodystrophy.

\section{Investigations showed:}

Haemoglobin $11 \mathrm{~g} / \mathrm{dl}$, WCC $12 \times 10^{9} / 1$ platelet, $210 \times 10^{9} / 1$; ESR $75 \mathrm{~mm}$ in 1 st hour. Sodium 137 $\mathrm{mmol} / \mathrm{l}$; potassium $4 \mathrm{mmol} / \mathrm{l}$; urea $15 \mathrm{mmol} / \mathrm{l}$; creatinine $630 \mu \mathrm{mol} / \mathrm{l}$. Serum proteins $66 \mathrm{~g} / \mathrm{l}$ (albu$\min 34 \mathrm{~g} / \mathrm{l})$. Electrophoresis raised $\alpha_{1}$ and $\alpha_{2}$ globulins; serum immunoglobulins normal. Calcium (total) $2.04 \mathrm{mmol} / \mathrm{l}$, phosphorus $2.74 \mathrm{mmol} / \mathrm{l}$, uric acid $0.7 \mathrm{mmol} / \mathrm{l}$.
Complement data: $\mathrm{CH} 50, \mathrm{C} 3, \mathrm{C} 4$, alternative pathway, factor B-all normal. C3NeF negative. Immune complexes: (C1Q binding assay initially positive reversing to negative in 3 days). Serum anti-GBM antibody raised above controls. Other autoantibodies negative. ASO titre <1:50.

Radiology: Chest - extensive alveolar shadowing both lung fields, cardiac size normal; intravenous pyelogram - normal sized kidneys.

Bacteriology and virology: sputum, urine and blood culture negative; routine viral antibodies-no significant rise.

Renal biopsy (on the day of admission) and postmortem revealed $100 \%$ epithelial crescent formation with compression of the capillary tufts and extensive fibrin deposition. Immunofluorescent examination revealed linear deposition of $\mathrm{IgG}$ and $\mathrm{C}_{3}$ in the glomerular capillaries and Bowman's capsule (see Fig. 2). Electron microscopy showed neither subendothelial nor intramembranous dense deposits.

In view of the characteristic features of anti-GBM antibody nephritis she was treated with prednisolone $30 \mathrm{mg} /$ day, azathioprine $50 \mathrm{mg} /$ day and cyclophosphamide $150 \mathrm{mg} /$ day and transferred within $24 \mathrm{hr}$ of presentation to the Hammersmith Hospital where plasmaphoresis was performed on 18 occasions. On this therapy her recurrent haemoptysis settled although her renal function continued to deteriorate. Within 2 days she became anuric and required peritoneal dialysis. Unfortunately her subsequent progress was complicated by the rapid development of thrombocytopenia and leucopenia, presumably related to her immunosuppressive treatment; she developed broncho-pneumonia and subsequently died of a severe septicaemic illness unresponsive to any medication.

\section{Comment}

This patient was known to have had extreme facial wasting since childhood. Examination of 


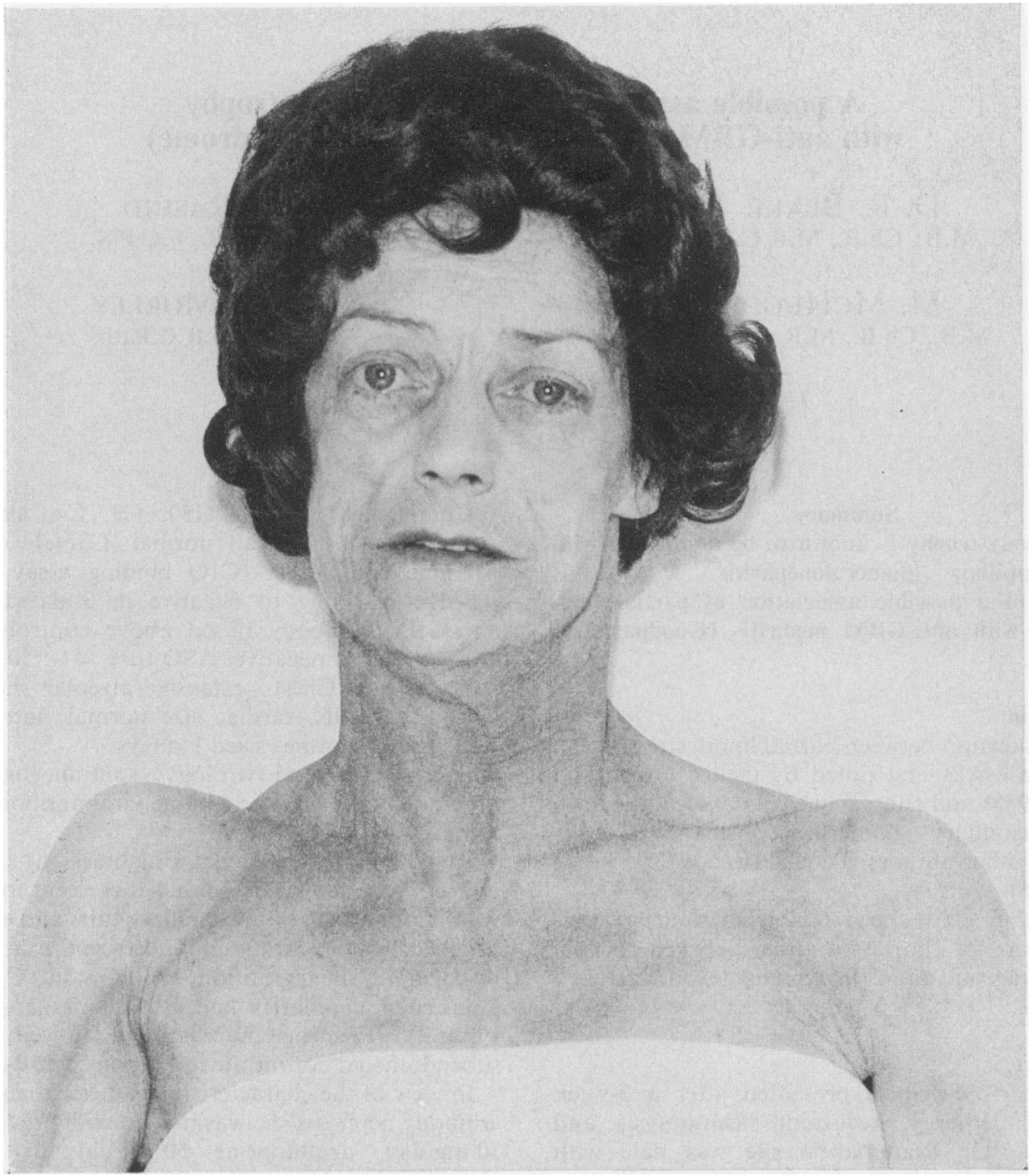

Fig. 1. Facial appearance demonstrating lack of subcutaneous fat.

family photographs confirmed the presence of partial lipodystrophy in her but not in her relatives. The loss of subcutaneous fat in the face and upper limbs contrasted sharply with its normal distribution in her lower limbs.

Associations of partial lipodystrophy with diabetes mellitus, Sjörgren's syndrome and disorders of lipid metabolism have been reported (Senior and Gellis, 1964; Alarcon-Segovia and Ramos-Niembro, 1976). Mesangio-capillary glomerulonephritis, especially with intramembranous dense deposits (dense deposit disease) has been recorded many times in association with partial lipodystrophy, with and without abnormalities of complement pathways (Peters et al., 1973; $\infty$ ) Sissons et al., 1976; Ooi, Vallota and West, 1976). N Anti-GBM disease, a condition characterized by a N severe form of glomerulonephritis with circulating ${ }_{-}$ antibodies to glomerular basement membrane, has not, so far as the authors know, yet been reported in association with partial lipodystrophy.

A patient has been described in whom these 2. conditions were found. Whether this is a trueo 


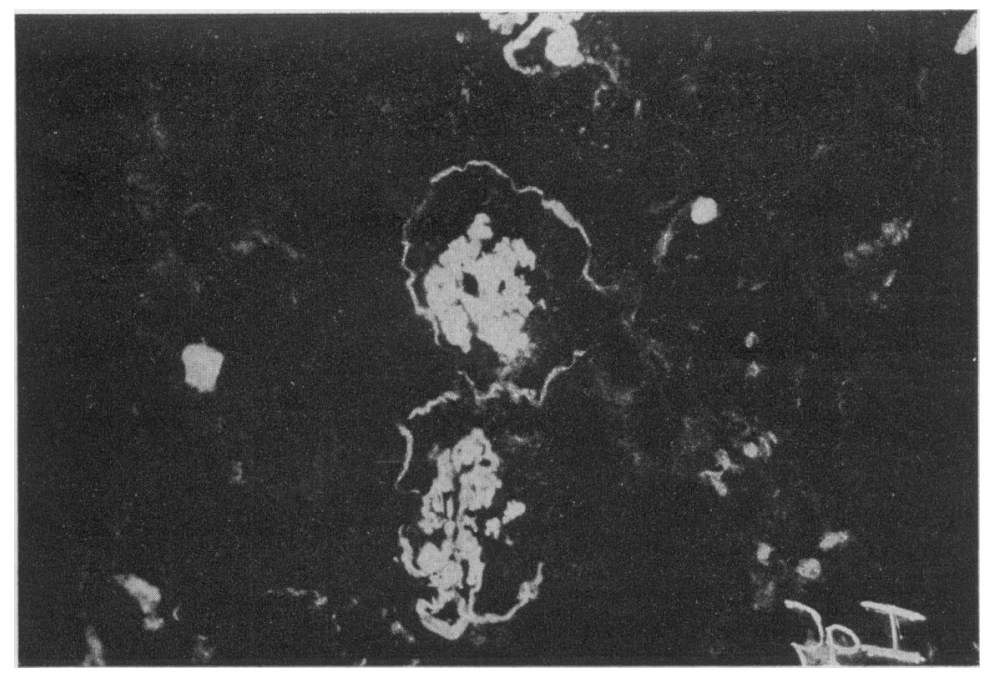

FIG. 2. Renal biopsy (immunofluorescence) demonstrating linear deposition of IgG in glomerular capillaries and Bowman's capsule.

association, or the chance co-existence of 2 rare conditions both known to be associated with forms of glomerulonephritis and both thought to have an immunological basis, remains to be seen.

\section{Acknowledgments}

We acknowledge the assistance of the staff of the Department of Renal Medicine, Hammersmith Hospital, in the management and investigation of this patient and thank Mr T. Vernazza for performing the complement assays, and $\operatorname{Dr}$ R. Wilkinson for permission to report this case.

\section{References}

Alarcon-Segovia, D. \& Ramos-Niembro, F. (1976) Association of partial lipodystrophy and Sjörgren's syndrome. Annals of Internal Medicine, 85, 474.
Gellis, S.S., Green, S. \& Walker, D. (1958) Chronic renal disease in children with lipodystrophy. American Journal of Diseases of Children, 96, 605.

OoI, Y.M., Vallota, E.H. \& West, C.D. (1976) Classical complement pathway activation in membrano-proliferative glomerulonephritis. Kidney International, 9, 46.

Peters, D.K., Williams, D.G., Charlesworth, J.A., Boulton Jones, J.M., Sissons, J.G.P. \& Evans, D.J. (1973) Mesangio-capillary nephritis, partial lipodystrophy and hypocomplementaemia. Lancet, ii, 535.

Senior, B. \& Gellis, S.S. (1964) The syndrome of total lipodystrophy and of partial lipodystrophy. Pediatrics, 33, 593.

Sissons, J.G.P., West, R.J., Fallows, J., Williams, D.G., Boucher, B.J., Amos, N. \& Peters, D.K. (1976) The complement abnormalities of lipodystrophy. New England Journal of Medicine, 294, 461. 